\title{
A Comparative Study of Effectiveness of Low Dose Magnesium Sulphate in Control of Convulsions in Eclampsia \& Prevention of Convulsions in Imminent Eclampsia
}

\author{
Asmita Nayak $^{1 *}$, Suniti Verma ${ }^{2}$, Kamlesh Yadav ${ }^{3}$, K.C. Nayak ${ }^{4}$ \\ ${ }^{1 *}$ Senior Resident, ${ }^{3}$ Professor, Department of Obstetrics \& Gynaecology, 4Principal \& Senior Professor, \\ Department of Medicine, S. P. Medical College \& AG Hospital, Bikaner, Rajasthan, India. \\ 2Professor, Department of Obstetrics \& Gynaecology, \\ Janana Hospital, SMS Medical College, Jaipur, Rajasthan, India.
}

\section{ABSTRACT}

Background: Eclampsia (Greek for "shining forth") is an acute and life-threatening complication of pregnancy, characterized by the appearance of tonic-clonic seizures, usually in a patient who has developed pre-eclampsia. Present study was conducted to determine effectiveness of low dose magnesium sulphate in control of convulsions in eclampsia \& prevention of convulsions in imminent eclampsia.

Material \& Methods: The prospective hospital based study was conducted in S.P.M.C, Bikaner. The subjects were divided into two groups on the basis of standard and low dose regime of $\mathrm{MgSO}_{4}$. Data were analysed using SPSS software.

Results: The present study showed Antepartum convulsion was present in 93 females and out of them 45 and 48 belonged to study and control group while remaining 107 females had imminent eclampsia and the difference was found statistically insignificant $(p>0.05)$.

Conclusion: Magnesium sulphate's narrow therapeutic range mandates that it only be used in the minimum doses which

\section{INTRODUCTION}

Eclampsia is a common cause of maternal mortality worldwide but particularly in the developing countries. It is estimated that every year eclampsia is associated with about 50,000 maternal deaths ( 10\% of MMR) worldwide, most of which occur in developing countries 1

Pre-eclampsia/eclampsia (PE/E) is one of the most common causes of maternal and perinatal morbidity and mortality in low and middle socio-economic status countries ${ }^{2}$. The first and foremost thing in management of eclampsia is control of convulsions. Magnesium sulphate has established itself as the drug of choice for the anticonvulsant management of eclampsia but the question as to what constitutes the minimum effective dose remains unanswered which is evident from the different regimens used in clinical practice. Its narrow therapeutic range mandates that it only be used in the minimum doses which gives efficient control of convulsions and helps in improving maternal and fetal outcome. Pritchard showed that magnesium serum concentration required for eclampsia prevention or treatment should be higher than normal serum levels, and suggested that therapeutic concentration should be between 4 and $7 \mathrm{mEq} / \mathrm{L}^{3}$. gives efficient control of convulsions and helps in improving maternal and foetal outcome.

Keywords: Antemartum, Convulsions, Eclampsia, Preeclampsia.

\section{*Correspondence to:}

Dr Asmita Nayak

Senior Resident, Department of Obstetrics \& Gynaecology,

S. P. Medical College \& AG Hospital,

Bikaner, Rajasthan, India

\section{Article History:}

Received: 12-07-2016, Revised: 01-08-2016, Accepted: 10-08-2016

\begin{tabular}{|l|c|}
\hline \multicolumn{2}{|c|}{ Access this article online } \\
\hline Website: & Quick Response code \\
www.ijmrp.com & \\
\hline DOI: & \\
10.21276/ijmrp.2016.2.5.048 & \\
\hline
\end{tabular}

Magnesium sulphate $\left(\mathrm{MgSO}_{4}\right)$ was first introduced to control convulsions in 1925. Dr. J.A. Pritchard in 1955, introduced magnesium sulphate for control of convulsions in eclampsia and is used worldwide ${ }^{3}$. Magnesium sulphate acts on peripheral myoneural junction and blocks the impulse transmission. Different magnesium sulphate dose protocols have been used in treating eclampsia, amongst which, Pritchard regime is widely used 3 .

It has been established that magnesium sulphate is the anticonvulsant of choice for both prevention and treatment of eclampsia. $\mathrm{MgSO}_{4}$ in the Pritchard regime is associated with dose- related toxicity. Potential hazards include maternal hypotension, respiratory depression, and respiratory arrest (cardiac arrest is rare). Undue apprehension regarding these hazards leads to a limited use of the drug in many low-income countries. Reducing magnesium sulphate toxicity without compromising its efficacy in controlling seizures and lowering mortality rates remains a major challenge ${ }^{4}$. The aim of this study to effectiveness of low dose magnesium sulphate in control of convulsions in eclampsia \& prevention of convulsions in imminent eclampsia. 


\section{MATERIALS \& METHODS}

The prospective hospital based study was conducted in the department of Obstetrics and Gynecology, P.B.M and Associated Group of Hospitals, attached to Sardar Patel Medical College, Bikaner tertiary hospitals during the study period of one year from January 2014 to December 2014.

\section{Inclusion Criteria}

- All cases of eclampsia (Ante partum / Intrapartum /Intercurrent).

- All cases of imminent eclampsia (hypertension with frontal headache, epigastric pain, vomiting and blurring of vision).

\section{Exclusion criteria}

- Patients who had received anticonvulsant treatment before admission to the hospital.

- Post-partum eclampsia.

- Patients already treated outside with magnesium sulphate.

- Those who presented with complications like renal failure, HELLP Syndrome, DIC, shock, massive pulmonary edema.

- Other causes of convulsions like epilepsy, meningitis, encephalitis and cerebrovascular accident (CVA), metabolic abnormalities.

\section{Sample Size}

Hundred cases of antepartum and imminent eclampsia.

\section{Sampling technique}

Simple random sampling was used.

\section{DATA COLLECTION}

\section{Study tools}

A semi-structured pre-tested proforma was used for collection of information. The subjects were divided into two groups on the basis of standard and low dose regime of $\mathrm{MgSO}_{4}$.

Group I (control) patient received magnesium sulphate by Pritchard regimen.

Group II (case) patient received low dose magnesium sulphate.

Group I (control)

\section{Eclampsia}

a. Loading dose: Magnesium sulphate $4 \mathrm{gm}$ intravenous in dilution over 4-5 minutes, followed by $10 \mathrm{gm}$ deep IM (5gm into each buttock).

b. Maintenance dose: $5 \mathrm{gm}$ IM into alternate buttock 4 hourly till 24 hrs after delivery / last convulsion whichever was later.

2. Imminent Eclampsia

a. Loading dose: $10 \mathrm{gm}$ deep IM (5gm into each buttock)

b. Maintenance dose: $5 \mathrm{gm}$ IM into alternate buttock 4 hourly till 24 hrs after delivery/till premonitory symptoms and signs disappeared.

\section{Group II (Case)}

1. Eclampsia

a. Loading dose: Magnesium sulphate $3 \mathrm{gm}$ intravenous in dilution (as above) over 4-5 minutes, followed by $5 \mathrm{gm}$ deep IM (2.5gm into each buttock).

b. Maintenance dose: $2.5 \mathrm{gm}$ IM into alternate buttock 4 hourly till 24 hours after delivery /last convulsion whichever later.

2. Imminent Eclampsia

a. Loading dose: $5 \mathrm{gm}$ deep IM (2.5gm into each buttock).

b. Maintenance dose: $2.5 \mathrm{gm}$ IM into alternate buttock 4 hourly till 24 hours after delivery/till premonitory symptoms and signs disappeared.

If there is a seizure recurrence later than 30 minutes after administration of the loading dose, an additional dose of $1 \mathrm{~g}$ was administered intravenously. Efficacy of the low dose regime was assessed by control of convulsions \& by noting the total quantity of magnesium sulphate required for the same.

All women were monitored by clinical parameters i.e. the knee jerk (should be present), respiratory rate (should be more than $16 /$ minute), and urine output (should be more than $25 \mathrm{ml} / \mathrm{hr}$ ) during maintenance period. If any toxicity was noted, then next dose of $\mathrm{MgSO}_{4}$ was withheld \& the toxicity was managed with calcium gluconate infusion.

The approval of the hospital's ethics is obtained prior to the commencement of study. Informed consent was obtained from each woman recruited into study. All cases were managed according to the departmental protocol and follow up clinically until they were discharged.

\section{Statistical Analysis}

Data were analysed using SPSS software. Chi square and student't' test were applied as and when required. $P$ value of $<0.05$ is considered as significant.

\section{RESULTS}

The present study showed mean age in study group females was $23.99 \pm 4.08$ years while in control group it was $23.27 \pm 3.92$ and the difference was found statistically insignificant $(p>0.05)$ (table 1). Antepartum convulsion was present in 93 females and out of them 45 and 48 belonged to study and control group while remaining 107 females had imminent eclampsia and the difference was found statistically insignificant ( $p>0.05$ ) (table 2).

In present study, recurrence of convulsion was present in only 10 females and out of them 6 belonged to study group and 4 belonged to control group and this difference was found statistically insignificant $(p>0.05)$ (table 3 ).

Table 1: Distribution of cases according to age group

\begin{tabular}{|c|c|c|c|c|c|c|}
\hline \multirow{3}{*}{$\begin{array}{l}\text { Age Group } \\
\text { (Years) }\end{array}$} & \multicolumn{4}{|c|}{ Group } & \multicolumn{2}{|c|}{ Total } \\
\hline & & & & & & \\
\hline & No. & $\%$ & No. & $\%$ & No. & $\%$ \\
\hline$\leq 20$ & 24 & 24.0 & 24 & 24.0 & 48 & 24.0 \\
\hline $2 \overline{1}-25$ & 51 & 51.0 & 61 & 61.0 & 112 & 56.0 \\
\hline $26-30$ & 18 & 18.0 & 10 & 10.0 & 28 & 14.0 \\
\hline$>30$ & 7 & 7.0 & 5 & 5.0 & 12 & 6.0 \\
\hline Total & 100 & 100 & 100 & 100 & 200 & 100 \\
\hline Mean & & & & & & \\
\hline SD & & & & & & \\
\hline$t$ & & & & & & \\
\hline$p$ & & & & & & \\
\hline
\end{tabular}


Table 2: Distribution of cases according to antepartum convulsion

\begin{tabular}{|c|c|c|c|c|c|c|}
\hline \multirow{3}{*}{$\begin{array}{l}\text { Antepartum } \\
\text { convulsions }\end{array}$} & \multicolumn{4}{|c|}{ Group } & \multicolumn{2}{|c|}{ Total } \\
\hline & \multicolumn{2}{|c|}{ Study } & \multicolumn{2}{|c|}{ Control } & & \\
\hline & No. & $\%$ & No. & $\%$ & No. & $\%$ \\
\hline Yes & 45 & 45.0 & 48 & 48.0 & 93 & 46.5 \\
\hline No & 55 & 55.0 & 52 & 52.0 & 107 & 53.5 \\
\hline Total & 100 & 100 & 100 & 100 & 200 & 100 \\
\hline$\chi^{2}$ & & & & & & \\
\hline $\mathrm{P}$ & & & & & & \\
\hline
\end{tabular}

Table 3: Distribution of cases according to recurrence of convulsion

\begin{tabular}{cccccccc}
\hline Recurrence of & \multicolumn{3}{c}{ Group } & \multicolumn{3}{c}{ Total } \\
\cline { 2 - 5 } convulsions & Study & \multicolumn{3}{c}{ Control } & & No. \\
Yes & No. & $\%$ & No. & $\%$ & & $\%$ \\
No & 64 & 6.0 & 4 & 4.0 & 10 & 5.0 \\
Total & 100 & 94.0 & 96 & 96.0 & 190 & 95.0 \\
$\chi^{2}$ & & 100 & 100 & 100 & 200 & 100 \\
P & & 0.687 & & & & \\
\hline
\end{tabular}

\section{DISCUSSION}

Eclampsia is a common cause of maternal mortality worldwide but particularly in the developing countries. Magnesium sulphate is the drug of choice for prevention of seizures in the pre-eclamptic woman, or prevention of recurrence of seizures in the eclamptic woman.

It has been established that magnesium sulphate is the anticonvulsant of choice for both prevention and treatment of eclampsia. $\mathrm{MgSO}_{4}$ in the Pritchard regime is associated with doserelated toxicity. Potential hazards include maternal hypotension, respiratory depression, and respiratory arrest (cardiac arrest is rare). Undue apprehension regarding these hazards leads to a limited use of the drug in many low-income countries.

Despite the compelling evidence for the effectiveness of magnesium sulphate concern has been expressed about the safety of its administration and use, particularly in clinical environments where the capacity for patient monitoring is limited. These concerns can constrain initiation of treatment for all women with indicated need, or may impede sustaining therapy over the recommended timeline established for the particular regimen, once treatment has been initiated ${ }^{5,6}$.

Considering the low body mass index of Indian women, a low dose magnesium sulphate regime has been introduced by some authors. Pritchard suggested that the dose of magnesium sulphate should be limited in women who are known to be or appear to be small. With this in mind the dose of regime of magnesium sulphate can be modified and a standard protocol can be formulated to suit our Indian women whom an average weight much less than their counterparts in the western world7-9.

In present study recurrence of convulsion was present in only 10 females and of them 6 belonged to study and 4 belonged to control group and this difference was found statistically insignificant.

Similar results were obtained by low dose "Dhaka" magnesium sulphate regime to determine the recurrence convulsion rate 9 . Our study also similar to randomized controlled trial comparing in Azare, North eastern Nigeria in $2013^{10}$.

Euser $A$ et $a^{11}$ suggested that the specific mechanisms of action remain unclear, the effect of magnesium sulphate in the prevention of eclampsia is likely multi-factorial. Magnesium sulphate may act as a vasodilator, with actions in the peripheral vasculature or the cerebrovasculature, to decrease peripheral vascular resistance or relieve vasoconstriction. Additionally, magnesium sulphate may also protect the blood-brain barrier and limit cerebral edema formation, or it may act through a central anticonvulsant action.

\section{CONCLUSION}

Considering to our Indian women whom an average weight much less than their counterparts in western world. Low dose magnesium sulphate appeared to be sufficient to control and prevent convulsion effectively in eclampsia and imminent eclampsia. Magnesium sulphate's narrow therapeutic range mandates that it only be used in the minimum doses which gives efficient control of convulsions and helps in improving maternal and foetal outcome.

\section{REFERENCES}

1. Duley L. Maternal mortality associated with hypertensive disorders of pregnancy in Africa, Asia, Latin America and the Caribbean. Br J Obstet Gynaecol 1992;99:547-53.

2. Chesley LC. Hypertensive Disorders in Pregnancy. Williams Obstetrics (14th ed.). New York: Appleton Century Crofts, 1971; pp. 700 .

3. Pritchard JA. The use of the magnesium ion in the management of eclamptogenic toxemias. Surg Gynecol Obstet 1955; 100:131140.

4. Jana N, Dasgupta S, Das AK, santra D, Samantra B. Experience of a low-dose magnesium sulphate regimen for the management of eclampsia over a decade, Int J Gynecol Obstet 2013; 122(1):13-17.

5. Barua A, Mundle S, Bracken H, Easterline T, Winikoff B. Facility and personnel factors influencing magnesium sulphate use for eclampsia and pre-eclampsia in 3 Indian hospitals. Int J Gynecol Obstet 2011; 115(3):231-234.

6. Firoz T, Sanghvi H, Merialdi M, von Dadelszen P: Preeclampsia in low and middle income countries. Best Pract ResClin Obstet Gynaecol 2011; 25:537-548. 
7. Flower CA. Magnesium sulphate in toxemia of pregnancy-New dosage schedule based on body weight J.Obstet Gynecol 1962; 19: 315 .

8. Suman S, Shivanjali M, Ajit P. Low dosemagnesium sulphate therapy for eclampsia and imminent eclampsia- Regime tailored for Indian women. J. Obstet Gynecol India 2003; 53(6):546-550.

9. Begum R, Begum A, Johnson R. A low dose (Dhaka) magnesium sulphate regime for eclampsia. Acta Obstetricaet Gynecologica Scandiriavica 2001; 80(11):998-1002.

10. McDonald SD, Lutsiv O, Dzaja N, Duley L. A systematic review of maternal and infant outcomes following magnesium sulphate for pre-eclampsia/eclampsia in real-world use. Int $\mathrm{J}$ Gynaecol Obstet. 2012; 118(2):90-6.

11. Euser A, Cipolla M. Magnesium sulphate for the treatment of eclampsia: a brief review. Stroke 2009; 40:1169-1175.

\section{Source of Support: Nil. Conflict of Interest: None Declared.}

Copyright: ( ) the author(s) and publisher. IJMRP is an official publication of Ibn Sina Academy of Medieval Medicine \& Sciences, registered in 2001 under Indian Trusts Act, 1882.

This is an open access article distributed under the terms of the Creative Commons Attribution Non-commercial License, which permits unrestricted non-commercial use, distribution, and reproduction in any medium, provided the original work is properly cited.

Cite this article as: Asmita Nayak, Suniti Verma, Kamlesh Yadav, K.C. Nayak. A Comparative Study of Effectiveness of Low Dose Magnesium Sulphate in Control of Convulsions in Eclampsia \& Prevention of Convulsions in Imminent Eclampsia. Int $\mathrm{J}$ Med Res Prof. 2016; 2(5):222-25. 